neofilolog

Czasopismo Polskiego Towarzystwa Neofilologicznego

ISSN 1429-2173, 2019, NR 52/2, 263-277

$h t t p: / / d x . d o i . o r g / 10.14746 /$ n.2019.52.2.5

http://poltowneo.org/

Grażyna Małgorzata Griso

Uniwersytet im. Adama Mickiewicza, Poznań https://orcid.org/0000-0002-8295-6238 grazyna@scdantealighieri.com.pl

\title{
O TRUDNOŚCIACH GLOTTODYDAKTYKÓW Z KONCEPTUALIZACJĄ POJĘCIA ŚWIADOMOŚCI INTERKULTUROWEJ. REFLEKSJA METAGLOTTODYDAKTYCZNA
}

\author{
On the difficulties glottodidactics has with conceptualization \\ of intercultural awareness. A meta-glottodidactic reflection
}

With its focus on foreign language teaching/ learning as the subject of study, glottodidactics belongs to empirical sciences which not only refer to the reality perceived with the senses but also necessitates empirical verification. Glottodidactics, being in the development phase and striving to consolidate its status, requires relative consistency in its use of key terms. According to researchers representing the intercultural approach, cultural awareness is such term. For an autonomy-seeking science, precision and relative coherence in defining concepts are necessary not only in the external dimension, but also in the consolidation of knowledge which occurs in the process of scientific communication. Reviewing the literature on glottodidactics, the article shows the current state of research in the field of conceptualizing cultural awareness.

Keywords: cultural awareness, intercultural communicative competence, extension of a concept, content of a concept

Słowa kluczowe: świadomość kulturowa (SK), interkulturowa kompetencja komunikacyjna (IKK), zakres pojęcia, treść pojęcia 


\section{Wstęp}

Przedmiotem badań glottodydaktyki są takie zjawiska empiryczne, które poddane badaniu dostarczą wiedzy naukowej o zależnościach i prawidłowościach procesu przyswajania języka obcego. Zdaniem badaczy, którzy wyrośli w paradygmacie kulturowym, do zjawisk rzutujących na postęp w nabywaniu kompetencji komunikacyjnej w języku obcym (dalej JO) należy świadomość (inter)kulturowa ${ }^{1}$ (dalej SK) postrzegana bądź jako składnik IKK (np. Byram i in., 2002; Bennett, 2001; Fantini, 2009; Chen, 1997), bądź jako jej czynnik rozwojowy (np. Fantini, 2000: 28; Liddicoat, Scarino, 2003 w Liddicoat, Scarino, 2009: 18).

Celem artykułu jest analiza pojęcia świadomości kulturowej ze zwróceniem szczególnej uwagi na jego zakres i treść. Rozważania prowadzone są w oparciu o przegląd piśmiennictwa krajowego i zagranicznego, w tym bazując na artykułach przeglądowych oraz polemicznych, jak i oryginalnych pracach badawczych, $w$ tym artykuły przeglądowe oraz polemiczne, jak i oryginalne prace badawcze.

\section{Geneza pojęcia}

Zanim pojęcie świadomości kulturowej nabrało znaczenia w glottodydaktyce, termin ten pojawił się w środowisku amerykańskich antropologów poszukujących takich zmiennych istotnych w komunikacji, które wpływają na poprawę kontaktów międzykulturowych. Sferą odniesienia były początkowo relacje dyplomatyczne, a następnie również biznesowe.

W 1972 r. autor pojęcia kompetencji komunikacyjnej Hymes, zwrócił uwagę, że kompetencja komunikacyjna (dalej KK) w JO, oprócz wiedzy czysto językowej, obejmuje także zdolność posługiwania się JO $\mathrm{w}$ różnych sytuacjach społecznych (Deadorff, 2009: 322). Obok wiedzy, pojawił się termin „kompetencja”. Dzięki jego pracom w 1980 r. Canale i Swain stworzyli pierwszy model KK w JO, umieszczając pośród czterech subkompetencji także subkompetencję socjokulturową.

W międzyczasie na rolę samej samoświadomości oraz świadomości przedmiotu uczenia się w dydaktyce zwrócił uwagę Gattegno (1976, w Fantini, 2006), a w 1975 r. Adler uznał, że SK jest podstawowym narzędziem umożliwiającym transgresyjne formowanie się tożsamości interkulturowej² (Adler, 1975).

\footnotetext{
1 Termin „świadomość kulturowa” przyjęto celowo jako najbardziej ogólny, a jednocześnie podstawowy.

${ }^{2}$ Warto zwrócić uwagę, że Adler odwoływał się do koncepcji dezintegracji pozytywnej wybitnego polskiego psychiatry i humanisty Kazimierza Dąbrowskiego, a kontynuatorką myśli Dąbrowskiego i Adlera jest Kim, której prace są przytaczane często w literaturze glottodydaktycznej.
} 


\section{Aktualne ujęcia świadomości kulturowej w glottodydaktyce}

W glottodydaktyce pojęcie świadomości kulturowej (interkulturowej czy poprzezkulturowej) często traktowane jest w sposób bardziej holistyczny, jako synonim KI ${ }^{3}$ (Risager w Encykolopedii Byrama, 2013; Penz w Fenner, 2001: 104; Finkbeiner, 2002; Zarate, 2004: 12). Pojawiło się ono w latach 80. XX w. jako jedna z kluczowych zmiennych w licznych modelach IKK, wraz ze zwrotem kulturowym w lingwistyce stosowanej (Risager w Byram: 2013: 182). Aktualnie SK wzbudza zainteresowanie w wielu naukach społecznych ${ }^{4}, \mathrm{z}$ których to zasobów pojęciowych czerpie też sama glottodydaktyka. Gdy sięga do nauk antropologicznych, skupia się na zjawisku relatywizmu kulturowego (zagadnienie różnicy), a gdy dotyka pojęć należących do dziedziny psychologii społecznej i poznania społecznego, koncentruje się wokół zagadnienia stereotypów. Reprezentantami pierwszego ujęcia są m.in. Will Baker i Michael Byram, drugiego natomiast Susan Stempleski i Barry Tomalin oraz Stephanie Houghton. W większości koncepcji SK wskazuje się na jej nieodłączny wymiar, jakim jest refleksyjność, postrzegana jako narzędzie wglądu, które ma prowadzić do rozwoju rozumienia własnego Ja i własnej tożsamości (Byram, 2006; Fantini, Finkbeiner i Koplin, 2016; Risager w Byram, 2013: 181; Liddicoat i Scarino, 2009). Dlatego też, dopiero w latach 90. XX w., wraz z podejściem pedagogicznym i krytycznym w nauczaniu języków obcych, uznano świadomość kulturową za kluczowy czynnik w rozwoju, istotny dla IKK, postaw i tożsamości (np. Risager w Byram, 2013; Liddicoat i Scarino, 2009).

\section{Konceptualizacja jako przekładnia języka teorii na język empirii}

Bez względu na to czy podejmowane badania ukierunkowane są bardziej epistemologicznie czy prakseologicznie, każdy badacz musi zmierzyć się z niełatwym wyzwaniem przełożenia języka teorii na język empirii, a celem nadrzędnym jaki powinien mu przyświecać jest poszerzenie i pogłębienie wiedzy ogólnej. Dla jak najlepszej realizacji przedsięwzięcia nie może on zapominać, o tym że „zawieszone między teorią a empirią budowanie wiedzy glottodydaktycznej, dla dalszej swojej konsolidacji i rozbudowy wymaga odniesienia się do istniejącego już

\footnotetext{
${ }^{3}$ Chen (1997) zwraca uwagę na powszechne w literaturze utożsamianie SK z wrażliwością interkulturową, czy wręcz z kompetencją interkulturową

${ }^{4}$ Najliczniejsze badania empiryczne nad SK prowadzone jednak są w naukach medycznych, gdzie SK uznaje się za bardzo istotny czynnik wpływający na przebieg leczenia pacjentów z innych kultur oraz w naukach służących sferze biznesu. Ten ostatni typ badań dotyczą formy i treści treningów.
} 
stanu wiedzy" (Wilczyńska, Michońska-Stadnik, 2010: 23). Analiza obecnych w literaturze stanowisk jest też krokiem koniecznym w każdym pojedynczym badaniu empirycznym, którego autor chciałby zapewnić sobie wyjściowy model o wysokiej trafności teoretycznej. Dopiero po spełnieniu tego warunku pojedynczy badacz może przystąpić do konceptualizacji przedmiotu badań, poprzedzającej „niezwykle ważny wyznacznik jej wiarygodności” (Wilczyńska, Michońska-Stadnik, 2010: 116), jakim jest empiryczna weryfikacja jej wyników. Stanowiąc konstrukt teoretyczny, zmienna nieobserwowalna, jaką jest świadomość kulturowa, tak jak większość zjawisk będących przedmiotem badań glottodydaktyki, nie poddaje się łatwo operacjonalizacji. Zabieg przełożenia konceptu SK na język empirii, polegający na wyłonieniu istotnych wskaźników ${ }^{5}$, okazuje się zadaniem szczególnie trudnym, przede wszystkim ze względu na aktualny stan badań. Napotykane trudności mogą nawet niejednokrotnie skłaniać do powstrzymywania się od podejmowania badań empirycznych w zakresie KI w nauczaniu/uczeniu się (dalej N/U) JO.

Istnieje jeszcze jeden istotny powód, dla którego definiowanie pojęć jest ważne dla nauki będącej w fazie rozwoju, jaką jest glottodydaktyka. „Nieostrość zakresu oraz nieostrość i chwiejność sensu" (Pawłowski, 1978: 22) istniejących definicji, „do których badacz [...] powinien się odwołać” (tamże) utrudnia, fundamentalną dla konsolidacji wiedzy, komunikację naukową ${ }^{6}$.

Celem działań wiedzotwórczych jest formułowanie także praw ogólnych (zwanych niekiedy generaliami - Wilczyńska, Michońska-Stadnik, 2010: 23), pozwalających na opis i rozumienie zjawisk, dlatego glottodydaktyka, jak każda nauka, potrzebuje dobrych definicji, czyli takich, które spełniają nie tylko warunki formalne, ale i warunki użyteczności naukowej ${ }^{7}$. Do warunków tych należy, zarówno w przypadku nauk nomologicznych, jak i idiograficznych, określenie zakresu oraz treści definiowanych pojęć.

\section{Brak zgodności co do zakresu pojęcia świadomości kulturowej}

Rozbieżność, a jednocześnie brak precyzji w określaniu pojęć związanych z kulturowym aspektem komunikacji obcojęzycznej, prowadzi do częstego utożsamiania

\footnotetext{
${ }^{5}$ Mowa tu zarówno o wskaźnikach empirycznych, jak i definicyjnych.

${ }^{6}$ Rozumianą przez Dakowską jako właściwość nauki normalnej i określoną jako „forma interakcji grupowej, wykorzystująca do tego celu ... także wiedzę wspólną” (Dakowska, 2014: 67). 7 Użyteczność naukowa jakiegoś pojęcia/definicji oznacza jego „przydatność” w realizacji zadań, jakie stawia sobie glottodydaktyka jako nauka, czyli chodzi o to, „aby dysponowała pojęciami pozwalającymi na formułowanie zdań, które by mogły służyć do stwierdzenia jak najściślej określonych stanów rzeczy, które by zatem były zdaniami maksymalnie rozstrzygalnymi" (Pawłowski, 1978: 83).
} 
takich zjawisk jak: wrażliwość interkulturowa, świadomość interkulturowa, a nawet interkulturowa kompetencja komunikacyjna. Pomocne tu może być klasyczne rozróżnienie zakresu i treści pojęć. Zakresem pojęcia (nazwy), przypomnijmy, jest zbiór wszystkich desygnatów przez te nazwę oznaczonych (Pawłowski, 1978: 49). Bardzo wyraźne różnice dotyczące zakresu pojęcia SK wyrażają się w odmienności rozumienia aspektów, w jakich się ona przejawia. W jednej grupie znajdują się zwolennicy ograniczenia zakresu SK do aspektu kognitywnego (np. Chen i Starosta, 1998), a w drugiej ci badacze, którzy poszerzają zakres pojęcia, stawiając znak równości między SK a KI, czy wręcz IKK, włączając do jego zakresu również desygnaty o charakterze afektywnym i behawioralnym (np. Bennett, 2001). Do pierwszej grupy możemy zaliczyć koncepcję Fantiniego (2009), który SK zdecydowanie lokuje poza zakresem IKK, a także Chena i Starosty, którzy ustalają jej przynależność do procesów poznawczych, oraz Byrama (2002), dla którego pojęcie krytycznej świadomości interkulturowej stanowi kognitywny składnik IKK i bywa rozumiane jako metapoznawcza zdolność do autoanalizy czy metarefleksyjność (np. Scarino, Liddicoat, $2009)^{8}$. Za skrajny przykład stanowiska wśród badaczy drugiej grupy może posłużyć koncepcja Bennetta, który odnajdując w SK wszystkie trzy wymiary, w zasadzie uznaje tożsamość jej zakresu z zakresem pojęcia KI (Chen, 1997).

Poszerzenie zakresu pojęcia SK o desygnaty o charakterze behawioralnym z kolei zdaje się wynikać z zaliczania jej do kategorii kompetencji i utożsamianiu jej z KI. Przykładem może być koncepcja Bakera, który definiuje SK w ten oto sposób: „Świadomość interkulturowa to świadome rozumienie roli kulturowo ugruntowanych form, praktyk i ram odniesienia, jakimi może się cechować komunikacja interkulturowa oraz zdolność do zastosowania tego konceptu w praktyce w elastyczny i uwzględniający kontekst sposób, podczas komunikacji" (Baker, 2012: 68). Definicja Bakera wyraźnie wyznacza zarówno kognitywny, jak i behawioralny aspekt SK. Podobnie ukierunkowane rozumienie SK prezentują ci badacze, którzy zajmują się mediacją interkulturową, określając ją jako istotny wewnętrzny, poznawczy i wstępny etap kompetencji mediacyjnych (np. Zarate 2004; Buttjes i Byram, 1991). Mediator interkulturowy bowiem to osoba zdolna do wykorzystania wiedzy do interpretacji, ale i podejmowania skutecznych kroków naprawczych (Liddicoat, 2014: 260). Należy zauważyć, że o ile włączenie wymiaru behawioralnego do zakresu pojęć KI czy IKK wynika z

\footnotetext{
${ }^{8}$ Fakt, że motorem rozwoju jest refleksyjne myślenie ma podstawowe znaczenie nie tylko w koncepcjach, które zajmują się aspektem rozwojowym, ale również dla konceptualizacji pojęcia SK, bowiem umożliwia wyciągniecie wniosku o ich wspólnej poznawczej naturze. Jeśli oba procesy zachodzą w umyśle, ich silny związek może hipotetycznie pozwolić na przypisanie SK do procesów kognitywnych, a nie do emocjonalnych czy behawioralnych.
} 
tego, że obie właściwości rzeczywiście per definizione wyrażają się w działaniu, o tyle nie jest to już tak oczywiste w przypadku SK. Jeśli nawet mamy do czynienia z pewnym stopniem zależności, to nie jest wiadomym, czy ma ona charakter związku przyczynowego. Istnieje bowiem szereg zmiennych inferencyjnych, które determinują podejmowane działania komunikacyjne ${ }^{9}$, a tym samym wysoki poziom SK nie musi koniecznie prowadzić do sukcesu komunikacyjnego.

Kolejną niejasną kwestią jest uznanie aspektu afektywnego SK. W literaturze często odnajdujemy twierdzenie, że osoba świadoma kulturowo charakteryzuje się empatią emocjonalną, postawą ciekawości i otwartości czy pozytywnymi emocjami w stosunku do przedstawicieli innych kultur (np. Bennett, 2001: 7; Chen i Starosta, 1998: 33). Dla Bennetta (2001) pozytywne emocje są wskaźnikiem wysokiego poziomu SK, natomiast Baker (2012: 19) czy Chen i Starosta (1998) uważają wprawdzie, że wysoki poziom SK pomaga w rozwoju umysłu, empatii, tolerancji i wrażliwości, jednak mimo dużej współzależności oba zjawiska, zdaniem tych badaczy, są wyraźnie odrębne.

Omawiając funkcjonujące w literaturze przedmiotu definicje SK, warto zwrócić uwagę na te koncepcje, które poszerzają jej zakres o świadomość językową. I tak, Risager uważa, że wprawdzie świadomość kulturowa obejmuje elementy pozajęzykowe, ale oba rodzaje świadomości łączy podwójny cel: wspomaganie uczenia się JO oraz poszerzenie rozumienia kulturowej natury języka (Risager w Buttjes i Byram, 1991: 23). Risager (tamże) stawia pytanie wprost:„,W jakim sensie świadomość językowa jest częścią świadomości kulturowej, a w jakim sensie nie?", a Finkbeiner (2002: 8) twierdzi, iż ważne jest, żeby „wzrost świadomości kulturowej i świadomości językowej szedł ręka w rękę". W czołowym dokumencie FREPA (Framework of Reference for Pluralistic Approaches to Languages and Cultures, 2010) autorzy zaznaczają, że wspieraniu rozwoju świadomości kulturowej na lekcjach języka obcego powinna towarzyszyć dbałość o świadomość socjolingwistyczną i językową.

Pojęcie świadomości językowej w ostatnich dwudziestu latach powoli znajduje swoje miejsce pośród problemów badawczych glottodydaktyki. Związek tych dwóch pojęć postrzega się przede wszystkim w kategoriach wpływu obu reprezentowanych przez nie zjawisk na rozwój krytycznego uczestnictwa w kulturze (Buttjes i Byram, 1991; Guilherme, 2000). Barany (2016) dokonuje połączenia krytycznej świadomości kulturowej ze świadomością językową w postaci interkulturowej świadomości komunikacyjnej, jednak zauważa, że jakkolwiek oba zjawiska są wprawdzie istotne dla porozumienia, to jednak odnoszą się one raczej do relacji podmiotu z rzeczywistością

\footnotetext{
${ }^{9}$ Do takich zmiennych, naszym zdaniem należą czynniki afektywne (np. lęk w koncepcji Gudykunsta) czy motywacyjne.
} 
zewnętrzną ${ }^{10}$ niż do kompetencji językowej podmiotu ${ }^{11}$. I rzeczywiście pojedynczy badacze zajmujący się świadomością językową rzadko ujmują związek świadomości kulturowej i językowej jako wiedzę o tym, w jaki sposób i pod jakimi postaciami kultura przejawia się w języku i komunikacji - jak to czyni np. Candelier i jego zespół w dokumencie FREPA (2010).

W rzeczywistości brak świadomości kulturowej podczas uczenia się języka obcego oznacza brak rozumienia wpływu kultur na ich języki i komunikację językową, co „zmniejszając prawdopodobieństwo prawidłowej interpretacji działań komunikacyjnych" (Triandis, 1977 w Chen, 1997: 9), prowadzi do słabszego postępu w rozwoju IKK, m.in. w postaci uporczywego dążenia do tłumaczeń dosłownych. Jakże często praktycy spotykają uczących się, u których rozwój IKK jest hamowany przez niezrozumienie zjawiska nieprzekładalności znaczeń. 0 przejawach roli interkulturowej świadomości językowej w uczeniu się języka obcego, a raczej jej braku, najdobitniej pisze Bennet $w$ dodatku do sprawozdania z badań Fantiniego (2018) pod znamiennym tytułem „How Not to Be Fluent Fool: Understanding the Cultural Dimension of Language".

\section{Brak zgodności co do treści pojęcia świadomości kulturowej}

Treścią pojęcia będziemy nazywać, za Pawłowskim (1978: 9), zbiór cech wspólnych dla desygnatów nazwy i od innych przedmiotów/zjawisk go odróżniający. Otóż badaczy SK różni przed wszystkim to, jakie znaczenie przypisują samemu pojęciu, w zależności od niekiedy implicytnie tylko przyjmowanych założeń co do natury współcześnie zachodzących zjawisk kulturowych (Wang, 2014) przy czym kwestia ta wpływa też dalej na to, jak odróżniana jest wiedza od świadomości. Stąd też zamiast terminu świadomość kulturowa w komunikacji obcojęzycznej bywają alternatywnie stosowane lub traktowane jako komplementarne (Borghini w Houghton, 2014: 117) takie określenia jak: (mono)cultural awareness, intercultural awareness, transcultural awareness czy critical intercultural awareness. Odrębność pojęcia krytycznej świadomości interkulturowej tłumaczy odmienność perspektywy badawczej natomiast pierwsze trzy nazwy odzwierciedlają odmienne rozumienia zarówno pojęcia kultury, jak i kompetencji kulturowej, jej relacji z językiem, a nawet sposobów jej kształcenia. Przy głębszej analizie różnice między tak często utożsamianymi ze sobą lub po prostu mylonymi terminami mogą okazać się bardzo istotne. Wszystkie

\footnotetext{
${ }^{10}$ Naszym zadaniem, autor odnosi się do Byramowskiego konceptu citizenship).

11 Tematyce tej poświęcona była również konferencja ALA ( Association for Language Awareness), pt. "Towards Language Aware Citizenship", która odbyła się w Amsterdamie e dniach 4-7.07.2018r.
} 
trzy określenia można potraktować też jako etapy rozwoju samej kompetencji interkulturowej, jak czynią to zwłaszcza ci badacze, którzy podkreślają znaczenie procesów transgresyjnych dla rozwoju kompetencji kulturowej w JO (np. Mayers w Buttjes i Byram, 1991: 142-143; Jongewaart, 2001 i in.). W rozwoju kompetencji kulturowej wyróżnia się 4 fazy, które ewoluują od świadomości, a zarazem kompetencji monokulturowej, poprzez cross-cultural competency ${ }^{12}$, kompetencję interkulturową, aż do transkulturowej. W kompetencji monokulturowej, zwanej we wcześniejszych pracach po prostu świadomością kulturową (Dasli, 2011), a charakteryzującej się działaniami komunikacyjnymi manifestującymi się etnocentryzmem ${ }^{13}$, punktem odniesienia jest własna kultura. Kształcenie świadomości międzykulturowej (cross-cultural competency) opiera się na budowaniu wiedzy dotyczącej różnic pomiędzy jasno określonymi kulturą wyjściową (dalej K1) i kulturą docelową (dalej K2), a wynikającymi z nich, zasadniczo socjolingwistycznymi umiejętnościami komunikacyjnymi. Wzorem do naśladowania jest tu native speaker, a dany język i kultura są ściśle ze sobą powiązane. Kompetencja interkulturowa natomiast, to zdolność do komunikacji między reprezentantami dialogicznie współzależnych kultur, odwołująca się raczej do bardziej elastycznego ujęcia kultury i podmiotowej roli w uczeniu się osobistej interpretacji znaczeń. Świadomość transkulturowa, „oddalając się od cross-kulturowych porównań" (Baker, 2009), nawiązuje do kategorii uniwersalnych, luźnych relacji między językiem a kulturą, a ponadto do wartości, jaką stanowi kompetencja różnojęzyczna ${ }^{14}$.

Brak zgodności, co do treści pojęcia, wiąże się także bezpośrednio z pytaniem o to, jaką rolę w procesie dydaktycznym nastawionym na rozwój SK powinno odgrywać zaznajamianie uczących się z konkretną i określoną wiedzą o K2, a jaka rola przypada kształceniu ponadkulturowemu i niespecyficznemu rozumieniu zależności między komunikacją a kulturą. Istotne rozbieżności między powyższymi podejściami wynikają z pojawiającego się coraz częściej w literaturze (Risager w Byram, 2013: 182) rozróżnienia między świadomością a

12 Dla pojęcia cross-cultural competency aktualnie brak odpowiednika polskiego; natomiast cross-cultural approach (jako podejście do nauczania kultury) bardzo trafnie określa Piątkowska - jako podejście kontrastywne..

${ }^{13}$ Etnocentrym za Bennetem (2001) rozumiemy jako niepodawanie pod wątpliwość przekonań i praktyk nabytych w pierwotnej socjalizacji i uznawanie ich za jedynie słuszne.

${ }^{14}$ Jeśli weźmiemy pod uwagę, że ww. rozumienia pojęcia świadomości mogą stanowić fazy rozwoju KI, okaże się, że z łatwością możemy im przypisać odpowiednie etapy rozwoju wrażliwości interkulturowej, jakie występują w procesualnym modelu Miltona Bennetta. I tak, świadomości monokulturowej odpowiadałaby faza zaprzeczenia, obrony lub minimalizacji; cross-cultural awareness - fazie akceptacji; świadomości interkulturowej - faza adaptacji, a świadomości transkulturowej - faza integracji. 
wiedzą (np. Tomlinson i Masuhara, 2004 w Wang, 2014: 37). W opinii Sercu (2004: 76) interpretowanie SK w kategoriach wiedzy specyficznej o K2 stanowi nadal dominującą tendencję $w$ aktualnych teoriach edukacyjnych, jednak w glottodydaktycznych badaniach naukowych coraz częściej, wraz ze zmianami w obrazie kulturowym współczesnego społeczeństwa, obecne są głosy wskazujące na konieczność uwzględnienia podejścia transkulturowego ${ }^{15}$. Taką zmianę postulują zwłaszcza glottodydaktycy zajmujący się dydaktyką języka angielskiego jako lingua franca. I tak na przykład Liddicoat (2002) identyfikuje dwa spojrzenia na SK: statyczne i dynamiczne. To pierwsze nie uznaje ścisłej łączności języka i kultury i oznacza przekazywanie informacji faktograficznych o kulturze K2. To drugie z kolei uwzględnia świadomość współzależności języka i kultury, wiedzę dotyczącą K1, a dzięki istnieniu różnicy w stosunku do K2, wiąże się z procesami rozumienia zachowań własnych i cudzych tą różnicą uwarunkowanych. W publikacji z 2009 r. Liddicoat i Scarino (MalczewskaWebb, 2014) nawiązują do wcześniejszego rozróżnienia między świadomością kulturową a zawierająca w sobie element transformacyjny świadomością interkulturową. Ta pierwsza dotyczy wiedzy o K2, podczas gdy ta druga dotyczy relacji między K1 a K2 obecnej w umyśle uczącego się. Według Sercu wiedza specyficzna będzie oznaczała wiedzę o powierzchownych cechach kultury ${ }^{16}$ (Chen i Starosta, 1998: 31), a wiedza ogólna to wiedza o subtelnych oraz znaczących cechach, które istotnie odbiegają od naszego systemu wartości i dlatego wymagają nieuniknionych zmian w samym podmiocie.

Zdaniem Fantiniego (2009) różnica między treścią pojęcia wiedzy a zjawiskiem świadomości polega na tym, że wiedza deklaratywna, biorąc znikomy udział w podejmowanych działaniach, jest mało operacyjna. Druga różnica z tym związana jest taka, że wiedza może być łatwo zapomniana, natomiast uzyskanie awareness czyni ją aktywną. „,Raz uzyskana świadomość nie jest operacją odwracalną" i „kiedy ktoś staje się świadomym czegoś, z trudnością przestaje

15 Do takiego rozumienia SK zbliża się pojęcie inteligencji kulturowej, które pojawiło się w badaniach nad zdolnością do efektywnego funkcjonowania w biznesowym środowisku międzynarodowym w 2002 r. wraz z nowym narzędziem badawczym Cultural Intelligence Scale (CQS).

${ }^{16}$ Chen i Starosta (1998) do świadomości kulturowej włączają zarówno wiedzę, jak i świadomość, przy czym wiedzę o kulturze J2 traktują jako pierwszy poziom SK, określając ją jako „świadomość powierzchownych cech” (tamże: 31). Na tym poziomie świadomości dominują stereotypy, natomiast na drugim poziomie znajduje się „świadomość znaczących i subtelnych cech" (tamże: 32), odmiennych od K1. Drugi poziom czy też etap składa się z dwóch faz - konfliktu i akceptacji, kiedy to dochodzi do analizy różnic kulturowych, której efektem jest rozumienie przyczyny tychże różnic. W ostatniej fazie jesteśmy zdolni, dzięki empatii, przyjąć perspektywę odmienną i w pełni ją rozumieć. 
być tego świadomym" - pisze Alvino Fantini (2009: 458). Świadomość, koncentrując się na relacji Ja-świat (to ja jestem świadomy czegoś), ułatwia włączanie i odnoszenie jej przedmiotu do własnych poglądów i przekonań, co jest warunkiem formowania się tzw. osobistej kompetencji komunikacyjnej (Wilczyńska, 2002). Podobnego zdania są Tomlinson i Masuhara (2004, w Baker, 2009: 76), którzy dokonali rozróżnienia między statyczną „,wiedzą kulturową” a „percepcją kulturową". W uzasadnieniu autorzy wyjaśniają, że wiedza jest statyczna, nabywana od innych, np. w formie stereotypu, podczas gdy SK wypływa z naszego wnętrza, jest dynamiczna, podlega zmianom i pochodzi z doświadczania innej kultury. Dokonując przeglądu odnośnej literatury, łatwo zauważyć, że kategoria rozumienia odgrywa istotną rolę w koncepcie SK. Tak, na przykład, Chen i Starosta świadomość interkulturową definiują jako „rozumienie kulturowych norm i praktyk społecznych, które wpływają na to, jak myślimy i jak się zachowujemy" (1998: 28), a Tomlinson i Masuhara (w Ghorbani, 2012) jako stopniowo rozwijające się wewnętrzne rozumienie równości kultur.

Wymiar psychologiczny SK (obok społecznego - citizenship) podkreślany jest także przez badaczy reprezentujących perspektywę krytyczną, jak Byram i jego uczennica Guilherme (2000). W ramach tego wymiaru podmiot uczący się staje się świadomy własnych zmian tożsamościowych, które dzięki rozwojowi sprawności analizy, interpretacji i, oceny krytycznej prowadzą do tworzenia się tożsamości interkulturowej (np. Kim, 2009). Jak to ujmuje Fenner (2001: 6), „spotkanie obcej kultury jest postrzegane jako dialog i część procesu komunikacji, który wpływa na jego uczestników w dialektycznej współzależności, podczas której dochodzi do negocjacji znaczeń". Z kolei Finkbeiner (2002) podkreśla, że rozwój kulturowy jest jednocześnie rozwojem osobistym. Do badaczy, którzy wiążą SK z negocjowaniem tożsamości należy także Littlewood (w Baker, 2009: 77), dla którego ta umiejętność jest wyrazem najwyższego stopnia rozwoju SK.

\section{Podsumowanie}

Jeden z problemów, jakie często może napotkać badacz rozpoczynający eksplorację literatury odnoszącej się do zjawiska SK dotyczy pozostawania na poziomie opisu w kategoriach cech umysłu i emocji. Jakkolwiek metodologicznie byłby uzasadniony opis SK, który wyszczególnia wybrane cechy definicyjne ${ }^{17}$, w niektórych przypadkach można odnieść wrażenie, że mnożenie cech - często pozostających na poziomie hipotez- zamiast porządkować, wzmaga chaos pojęciowy. W efekcie sprzyja to percepcji SK jako konstruktu bardziej złożonego i skomplikowanego niż to jest w rzeczywistości. W takiej sytuacji nie może dziwić

${ }^{17}$ Dotyczy to ustalania treści pojęcia (Pawłowski, 1978). 
brak narzędzi do mierzenia SK. Nieliczne są badania empiryczne z wykorzystaniem metod ilościowych ${ }^{18}$, przy czym grupy pytań kwestionariuszy i skale mające służyć mierzeniu KI odnoszą się w nich do zupełnie różnego rozumienia SK. I tak, do mierzenia SK służą grupy wskaźników przejawiające się w niektórych przypadkach w wiedzy (np. Saville-Troike, 1978 - test wiedzy faktograficznej czy Corbita Global Awareness Profile (w Fantini, 2009) lub w postawach (Chen i Starosta, 2000) - Intercultural Sensitivity Skale), lub też w działaniach podejmowanych przez podmiot. Jeśli nawet przyjąć, że ustalone przez badaczy wskaźniki stanowią mierzalne manifestacje SK, pozostaje niejasną natura samego zjawiska. Otwarte też pozostaje pytanie o rzeczywiste powiązania między danymi wskaźnikami, a przecież ich odkrycie mogłoby przyczynić się do zrozumienia struktury pojęcia. $Z$ uwagi na to, że ujęcia te w większości przypadków pozostają na poziomie rozważań teoretycznych, nie budują one definicji operacyjnych i nie określają idących za nimi wskaźników. Jako takie, zdają się one być cenne dla rozwoju i pogłębiania wiedzy jedynie w pewnym zakresie.

Odnosząc się z kolei do trudności, jakie może w związku z brakiem zgodności zakresu i treści pojęcia SK napotkać badacz, należy zaznaczyć, że nie chodzi tu o dążenie do unifikacji wszystkich definicji ani wykluczenie współzależności trzech aspektów KI. Taka zbieżność/identyczność definicji zresztą nie byłaby ani możliwa, ani słuszna. Racjonalne wydaje się dążenie do pewnego stopnia zgodności definicji, które wynika z przekonania, iż ich zbytnia rozbieżność prowadziłaby w każdym przypadku do niskiej trafności teoretycznej ewentualnych badań empirycznych. W konsekwencji brak byłoby podstaw do intersubiektywnej komunikowalności, która jest wartościowa i zasadnicza dla wszystkich etapów procedury badawczej, a nie tylko końcowych wyników.

Współcześnie spotyka się też pogląd, że występująca w literaturze przedmiotu znaczna odmienność w definiowaniu wskaźników KI czy świadomości kulturowej nie musi koniecznie oznaczać defektu metodologicznego. Intuicyjne rozumienie pojęcia, mimo owej różnorodności, może być uzasadnione wzajemną wymienialnością wskaźników ${ }^{19}$. Poza tym, jak twierdzi Komorowska „W SLA i FLT precyzja terminologiczna jest czasami uznawana bardziej za ograniczenie niż wartość" (Komorowska, 2013: 8). Jedną z możliwych przyczyn takiego stanu rzeczy, badaczka widzi w tym, że na miejsce „starego" paradygmatu - który dążył do spójności i precyzji definicyjnej w ramach jednego zagadnienia - pojawił się nowy, zgodnie z którym tworzenie nowych terminów

\footnotetext{
${ }^{18}$ Przeważają badania typu action research, np. Finkbeiner, (2002), Fantini, (2006).

${ }^{19}$ Wzajemną wymienialność wskaźników Babbie określa w następujący sposób: „jeśli kilka różnych wskaźników reprezentuje w pewnym stopniu to samo pojęcie, będą one wszystkie zachowywać się tak, jak zachowywałby się owo pojęcie" Babbie: 149).
} 
bez jasnej i wyraźniej definicji także może być celowe, ponieważ prowadzi do niekończącej się debaty nad znaczeniem danego terminu z nadzieją, że utworzenie spójnej koncepcji przyjdzie później. Komorowska określa to zjawisko jako „postmodernistyczny rozwój teorii”(tamże: 9). Drugim, nie wykluczającym się z pierwszym, wyjaśnieniem takiego stanu rzeczy może być natura samego zjawiska, zmuszająca nas do sięgnięcia po wiedzę pochodzącą z nauk ościennych, co wymaga dodatkowego nakładu pracy.Oceniając krytycznie jakość „postępowania dostowawczego" (Wilczyńska, Michońska-Stadnik, 2010: 70) Komorowska pisze dalej „Kiedy wprowadzamy nowy koncept do SLA czy FLT z innych dyscyplin odnoszenia się do tej dyscypliny, kończy się często tylko wskazaniem, że tak jest” (Komorowska, 2013: 7). „Nasza dyscyplina niestety -kontynuuje Komorowska - opiera się na modelach wygodnych, bo licznych i niefalsyfikowalnych, a praktycy ciągle czekają na konkluzywne teorie" (Komorowska, 2013: 7).

Wracając do kwestii świadomości kulturowej, mimo że zdaniem wielu glottodydaktyków stanowi ona jeden z celów nauki JO, ograniczenie do badań podstawowych skutkuje brakiem dostatecznej ilości prac empirycznych nad jej wpływem na IKK, czynnikami jej rozwoju czy opisem struktury i zależności między cechami pojęcia (Chen, 1997). Jednymi z niewielu wyjątków są badania opierające się na podejściach zorientowanych na tekst (np. Jones, $1995 \mathrm{w}$ Baker, 2009). Ponadto, część badaczy definiuje SK poprzez opis tego, w jaki sposób można pomóc uczącym się w jej rozwoju, jak czyni to np. Guilherme (2000) czy Finkbeiner (2002) w modelu $A B C^{20}$.

Jak wynika z naszej analizy, unikanie definiowania wymienionych pojęć, a szczególnie brak definicji operacyjnych, prowadzi w rezultacie do wyłączenia danych zjawisk z badań empirycznych. Co więcej, fakt ten w konsekwencji uniemożliwia korektę konceptów/teorii, znacząco ograniczając nasze szanse na postęp w rozwoju wiedzy/nauki.

Wprawdzie jak pisze Babbie „Wyjaśnianie pojęć jest w naukach społecznych procesem nieskończonym" (2013: 150), jednak tworzenie ładu pojęciowego wydaje się być szczególnie istotne dla każdej nauki znajdującej się w fazie rozwoju, w tym także dla glottodydaktyki.

\section{BIBLIOGRAFIA}

Adler P. (1975), The transition experience: An alternative view of culture shock. Online: https://www.researchgate.net/publication/232593393_The_transition_experience_An_alternative_view_of_culture_shock [DW 21.03.2019]

\footnotetext{
20 Model ABC jest bardzo interesującą, holistyczną i dynamiczną propozycją dydaktyczną dydaktyką zmierzającą do rozwoju KI.
} 
Babbie E. (2013), Podstawy badań społecznych. Warszawa: Wydawnictwo Naukowe PWN

Baker W. (2015), Culture and Identity through English as a Lingua Franca: Rethinking Concepts and Goals in Intercultural Communication. Berlin: Walter de Gruyter. Baker W. (2012), From cultural awareness to intercultural awareness: Culture in ELT. (w) „ELT Journal”, nr 66.1, str. 62-70.

Baker W. (2009), Intercultural awareness and intercultural communication through English: an investigation of Thai English language users in higher education. Online: https://eprints.soton.ac.uk/66542/1/Will_Baker_PhD_Jan_2009_final.pdf [DW 26.09.2017]

Barany L.K. (2016), Language Awareness, Intercultural Awareness and Communicative Language Teaching: Towards Language Education. (w) „International Journal of Humanities and Cultural Studies", nr 2 Online: https://www.ijhcs.com/ index.php/ijhcs/article/view/183. [DW 7.11.2017]

Bennet M. (2006), How Not to Be Fluent Fool: Understanding the Cultural Dimension of Language. (w) Fantini A. (red.), Exploring and Assessing Intercultural Competency. Federation EIL. ResearchGate. Online: https://www.researchgate.net /publication/254663146_Exploring_and_Assessing_Intercultural_Competenc e/ [DW 4.11.2017]

Bennett M. (2001), Developing intercultural sensitivity: an integrative approach to global and domestic diversity. http://www.diversitycollegium.org/pdf2001/ 2001bennettspaper.pdf

Buttjes D., Byram M. (1991), Mediating Languages and Cultures: Towards an Intercultural Theory of Foreign Language. Clevedon: Multilingual Matters.

Byram M., Gribkova B., Starkey H. (2002), Developing the intercultural dimension in language teaching. Strasbourg: Council of Europe.

Byram M., Hu A. (2013), Routledge Encyclopedia of Lanuage Learning and Teaching. New York: Taylor\&Francis.

Byram M., (2006), Language and Identities. Strasbourg: Council of Europe.

Candelier M. i in. (2010), FREPA/CARAP Framework of Reference for Pluralistic Approaches to Languages and Cultures. Strasbourg: Council of Europe.

Chen G.-M. (1997), A review of concept of intercultural sensitivity. Online: https://digitalcommons.uri.edu/cgi/viewcontent.cgi?referer=https://www.google.com/ \&httpsredir=1\&article=1037\&context=com_facpubs. [DW 22.09.2017]

Chen G. M., Starosta W. J. (1998), A review of the concept of intercultural awareness. (w) „Human Communication”, nr 2, str. 27-54. Online: https://digitalcommo ns.uri.edu/cgi/viewcontent.cgi?referer=https://www.google.com/\&httpsredir $=1 \&$ article=1036\&context=com_facpubs (DW 21.09.2017]

Chen G. M., Starosta W. J. (2000), The development and validation of the intercultural communication sensitivity scale. (w) „Human Communication”, nr 3, str.1-15. Online: https://digitalcommons.uri.edu/cgi/viewcontent.cgi?referer=https://www.google .com/\&httpsredir=1\&article=1035\&context=com_facpubs [DW 21.09.2017]

Dakowska M. (2014), o rozwoju dydaktyki języków obcych jako dyscypliny naukowej. Warszawa: Wydawnictwo Uniwersytetu Warszawskiego. 
Dasli M. (2011), Reviving the 'moments': from cultural awareness and cross-cultural mediation to critical intercultural language pedagogy. (w) „Pedagogy, Culture \& Society", nr 19(1), str. 21-39. Online: https://www.researchgate.net/publication/238600397_Reviving_the_'moments'_From_cultural_awareness_and_cr osscultural_mediation_to_critical_intercultural_language_pedagogy [DW 21.03.2019]

Fantini A. (2018), Intercultural Communicative Competence in Educational Exchange: A Multinational Perspective. New York: Routledge.

Fantini A. (2009), Assessing Intercultural Competence: Issues and Tools (w) Deardorff C. (red.), The SAGE Handbook of Intercultural Competence. London: SAGE Publication str. 456-538.

Fantini A. (2006), Exploring and Assessing Intercultural Competency. Federation EIL. ResearchGate. Online: https://www.researchgate.net/publication/25466314 6_Exploring_and_Assessing_Intercultural_Competence/[DW 3.11.2017]

Fenner A.B. (2001), Cultural awareness and language awareness based on dialogic interaction with texts in foreign language learning. Strasbourg: European Centre for Modern Languages Council of Europe. Online: http://citeseerx.ist.psu.edu/ viewdoc/download?doi=10.1.1.131.3821\&rep=rep1\&type=pdf [DW 29.11.2018]

Finkbeiner C., Koplin, C. (2002) A coopertative approach for faciliting intercultural education. ResearchGate. Online: https://www.researchgate.net/publication/36410771_A _cooperative_approach_for_facilitating_intercultural_education [DW 15.05.2017]

Ghorbani Z. (2012), Developing Cultural Awareness in Foreign Language Teaching. Online: http://www.ccsenet.org/journal/index.php/elt/article/view/15270 [DW 21.03.218]

Guilherme M.M.D. (2000), Critical cultural awareness: the critical dimension in foreign culture education. Online: https://core.ac.uk/download/pdf/108711.pdf [DW 5.05.2017]

Houghton S.A. (2012), Intercultural Dialogue i Practice Managing Value Judgment. Toronto: Multilingual Matters.

Jongewaard S. (2001), Beyond Multiculturalism: Towards a Unification Theory for the Improvement of Cross-Cultural Communication. Online: https://files.eric.ed.g ov/fulltext/ED453119.pdf. [DW 23.06.216]

Kim Y.Y. (2009) The Identity Factor in Intercultural Competence (w) Deardorff C. (red.), The SAGE Handbook of Intercultural Competence . London: SAGE Publication str. 121-178 Komorowska H. (2013), Language Awareness: From Embarras de Richesses to Terminological Confusion (w) Łyda A., Szcześniak K. (red.), Awareness in Action: The Role of Consciousness in Language Acquisition. New York: Springer, str. 3-20.

Liddicoat A. (2014), Pragmatics and intercultural mediation in intercultural language learning (w) „Intercultural Pragmatics”, nr 11(2), str. 259-277.

Liddicoat A., Scarino A. (2009), Teaching and Learning Languages A Guide. Online: www.tllg.unisa.edu.au [DW 23.08.2017]

Malczewska-Webb B. (2014), Cultural and intercultural awareness of international students at an Australian University. Online: https://epublications.bond.edu.a u/fsd_papers/60/ [DW 13.12.2018]

Pawłowski T. (1978), Tworzenie pojęć i definiowanie w naukach humanistycznych. Warszawa: PWN. 
Piątkowska K. (2015), From cultural knowledge to intercultural communicative competence: changing perspectives on the role of culture in foreign language teaching (w) „Intercultural Education”, nr 26, str. 397-408.

Sercu L. (2004), Assessing intercultural competence: A framework for systematic test development in foreign language education and beyond. Online: https://www. researchgate.net/publication/240532460_Assessing_intercultural_competen ce_A_framework_for_systematic_test_development_in_foreign_language_e ducation_and_beyond [DW 21.03.2019]

Tomalin B, Stempleski S. (2013), Cultural Awareness. Oxford: Oxford University Press.

Wang Y. (2014), Views and Attitudes of Staff and Students towards the Significance of Intercultural Awareness in Foreign Language Teaching and Learning in an Australian University Context. Online: https://eprints.utas.edu.au/18238/1/front-wang-2 014-thesis.pdf [DW 2.02.2016]

Wilczyńska W. (2004), Podmiotowość i autonomia jako wyznaczniki osobistej kompetencji komunikacyjnej (w) Wilczyńska W. (red.), Autonomia w dydaktyce języków obcych. Poznań: Wydawnictwo Naukowe UAM, str. 69-83.

Wilczyńska W., Michońska-Stadnik A. (2010), Metodologia badań w glottodydaktyce. Wprowadzenie. Kraków: AVALON.

Zarate G., Gohard-Radenkovic A., Lussier D., Penz H. (2004), Cultural mediation in language teaching and learning. Kapfenberg: Council of Europe. Online: http://citeseerx.ist.psu.e $\mathrm{du} /$ viewdoc/download?doi=10.1.1.132.7681\&rep=rep1\&type=pdf [DW 10.03.2018] 